EXTENDED REPORT

\title{
Atopic disorders in ankylosing spondylitis and rheumatoid arthritis
}

\author{
M Rudwaleit, B Andermann, R Alten, H Sörensen, J Listing, A Zink, J Sieper, J Braun
}

Ann Rheum Dis 2002;61:968-974

See end of article for authors' affiliations

Correspondence to DrM Rudwaleit,

Rheumatology,

Medizinische Klinik I,

Universitätsklinikum

Benjamin Franklin,

Hindenburgdamm 30

12200 Berlin, Germany;

rudwalei@zedat.fu-berlin.de

Accepted

27 February 2002

\begin{abstract}
Background: The prevalence of atopic disorders in ankylosing spondylitis (AS) is unknown. AS and rheumatoid arthritis (RA) exhibit divergent T helper (Th) cell cytokine patterns.

Objective: To test the hypothesis that Th2 polarised atopic disorders may be decreased in Th 1 polarised RA but increased in AS, which is characterised by an impaired Th 1 cytokine pattern, by assessing the prevalence of atopic disorders in AS and RA.

Methods: 2008 subjects (380 patients with AS, 728 patients with RA, 900 controls) from Berlin, Germany, were considered in this cross sectional study. A questionnaire incorporating questions from the European Community Respiratory Health Service (ECRHS) and the International Study of Asthma and Allergies in Childhood (ISAAC) protocol was mailed to all subjects. Disease severity was assessed by the modified Health Assessment Questionnaire (mHAQ).

Results: $1271(63.3 \%)$ people responded to the questionnaire. The prevalence of any atopic disorder was $24.6 \%(61 / 248)$ in patients with AS, $20.7 \%(111 / 536)$ in controls, and $13.1 \%(64 / 487)$ in patients with RA ( $p=0.0009$ for AS $\vee$ RA; $p=0.001$ for controls $v$ RA). Hay fever was reported by $40 / 248(16.1 \%)$ patients with AS, $82 / 536(15.3 \%)$ controls, and $42 / 487(8.6 \%)$ patients with RA $(p=0.002$ for AS $\vee R A ; p=0.001$ for controls $v$ RA). Atopic dermatitis was reported by 19/248 (7.7\%) patients with AS, $26 / 536(4.9 \%)$ controls, and $14 / 487(2.9 \%)$ patients with RA ( $p=0.003$ for AS $v$ RA), and asthma by $18 / 248(7.3 \%)$ patients with AS, 35/536 (6.5\%) controls, and $21 / 487(4.3 \%)$ patients with RA. The differences were related neither to age nor to drugs. Disease severity was less in atopic patients with RA who had the atopic disorder before the onset of RA (median mHAQ 0.75) than in patients in whom RA preceded the atopic disorder (median $\mathrm{mHAQ} 1.75 ; \mathrm{p}=0.027$ ).

Conclusions: Atopic disorders are decreased in RA but only slightly and non-significantly increased in AS. This may imply that atopy confers some protection from RA but only little if any susceptibility to AS. It may further indicate that the cytokine deviation towards an impaired Th1 pattern in AS is less strong than the cytokine deviation towards Th1 in RA, a finding which may affect future therapeutic approaches.
\end{abstract}

A nkylosing spondylitis (AS) is a systemic inflammatory disease affecting predominantly the axial skeleton but also the peripheral joints, entheses, the eye, and occasionally the aortic root. ${ }^{1}$ Rheumatoid arthritis (RA) is also a systemic inflammatory disease but in contrast with AS affects primarily the joints of the hand and feet in a symmetrical fashion. The primary site of inflammation in RA is the synovium but in AS appears to be the enthesis and sites where ligaments insert into bone. ${ }^{2}$ AS usually begins in the second or third decade whereas the onset of RA is rarely before the fourth decade. AS affects more men than women, which is in contrast with the female preponderance in RA. Both diseases result in substantial and almost equal morbidity. ${ }^{3}$

Atopic disorders comprise hay fever, allergic asthma, and atopic eczema/neurodermatitis and usually arise in early childhood. ${ }^{45}$ Key pathogenetic features of atopic disorders are raised levels of IgE and a characteristic $\mathrm{T}$ helper cell cytokine pattern. ${ }^{6}$ Among T helper cells (Th) two opposite poles of immune responses can be distinguished based on the secretion of cytokines: the Thl cytokine pattern with predominant secretion of interferon $\gamma($ IFN $\gamma$ ) and induction of a cellular immune response, and the Th2 cytokine pattern with predominant secretion of interleukin (IL) 4, IL5, and IL13 and induction of the humoral immune response. ${ }^{7}$ While atopic disorders are associated with a Th2 cytokine pattern, RA is considered to be a Thl polarised disease. ${ }^{6-11}$ The cytokine pattern of AS and other spondyloarthropathies with low production of IFN $\gamma$ and tumour necrosis factor $\alpha$ (TNF $\alpha)$ without relevant changes in IL4 production can best be described as an impaired Thl cytokine pattern. ${ }^{12}{ }^{13}$ It is therefore similar but not identical to that of atopic disorders and clearly different from that in RA.

The generation of a Thl immune response is inhibited in the presence of Th2 cytokines and vice versa. ${ }^{7}$ Based on the reciprocal inhibition of the development of Th1 and Th2 responses it has been suggested that Thl and Th2 polarised immune responses and also Thl and Th2 polarised diseases mutually exclude each other. ${ }^{14-17}$ Because the cytokine patterns in AS and RA are not restricted to inflamed tissue but to some extent a systemic feature of each disease ${ }^{1013}$ we suggested that the impaired Thl cytokine pattern in AS may well be compatible with the coexistence of atopic disorders whereas the strong Thl pattern in RA is less compatible with such coexistence. We therefore studied the prevalence of asthma, hay fever, and atopic eczema in large cohorts of patients with AS, patients with RA, and controls in West Berlin.

\section{PATIENTS AND METHODS}

Patients and controls

At the end of 1997, patients with RA and AS were identified from the German Rheumatological Database. ${ }^{3}$ Entries to this

Abbreviations: AS, ankylosing spondylitis; ECRHS, European Community Respiratory Health Survey; IFN $\gamma$, interferon $\gamma$; IL, interleukin; ISAAC, International Study of Asthma and Allergies in Children; mHAQ, modified Health Assessment Questionnaire; RA, rheumatoid arthritis; RF, rheumatoid factor; Th, T helper; TNF $\alpha$, tumour necrosis factor $\alpha$ 


\begin{tabular}{llll} 
Table 1 & \multicolumn{4}{l}{ Demographic data of patients and controls } \\
\hline & $\begin{array}{l}\text { Numbers } \\
(\mathrm{n})\end{array}$ & $\begin{array}{l}\text { Age (years) } \\
\text { (mean (SD)) }\end{array}$ & $\begin{array}{l}\text { Disease duration (years) } \\
\text { (mean (SD)) }\end{array}$ \\
\hline AS & 248 & $47.9(12.3)$ & $14.1(10.6)$ \\
RA & 487 & $60.3(12.5)$ & $12.2(9.7)$ \\
Controls & 536 & $49.8(15.6)$ & - \\
\hline
\end{tabular}

database are made voluntarily by rheumatologists at university hospital outpatient clinics, other rheumatology hospitals, or in private rheumatological practice. Diagnoses were made according to the 1987 American Rheumatism Association criteria (RA) and the 1984 modified New York criteria (AS). In order not to include in the RA group patients with spondyloarthropathies incorrectly diagnosed as "rheumatoid factor (RF) negative RA", only patients with RA who were positive for RF were selected from the database for this study.

Hospital staff members from the Benjamin Franklin Hospital $(n=750)$, of whom about half were involved in patient care and half in hospital administration, were chosen as controls. Elderly patients without any known inflammatory rheumatic disease who were attending an osteoporosis outpatient clinic $(n=150)$ were additionally selected as controls to allow comparisons, particularly with the RA group for whom a higher mean age was expected.

All patients and controls selected for this study were residents of West Berlin because differences in the prevalence of atopy between West and East Germany have been reported. ${ }^{18-20}$ Patients and controls willing to respond to the questionnaire were asked to indicate their name and address but could also respond anonymously in order to increase the response rate; this approach, however, did not allow a second contact to non-responders.

\section{Questionnaire}

During a three month period, from January to March 1998, a questionnaire was mailed to all patients and controls. The questionnaire comprised standardised questions extracted from the European Community Respiratory Health Survey (ECRHS $)^{21}$ and from the International Study of Asthma and Allergies in Children (ISAAC) protocol. ${ }^{22}{ }^{23}$ The ECRHS protocol assesses bronchial symptoms related to atopic asthma in adults. The ISAAC protocol has been designed primarily for allergies in children of various age. Therefore, the module for teenagers ( $>13$ years old) from the ISAAC protocol was chosen for this study to assess symptoms related to hay fever and atopic eczema. ${ }^{22}$ The individual sets of questions of the composed questionnaire have been validated in several countries including Germany ${ }^{19}$ and together with similar questionnaires successfully applied to assess the prevalence of atopic disorders without further testing in several large international surveys. ${ }^{53} 24$

Selected questions from the questionnaire had to be positively answered. These were for asthma "Have you had wheezing or whistling in your chest at any time in the past 12 months? If yes: Have you had this wheezing or whistling when you did not have a cold?" or alternatively "Have you had an attack of asthma in the past 12 months?"; for hay fever "In the past 12 months have you had a problem with sneezing, or a runny, or a blocked nose when you did not have a cold or the flu? If yes: Has this nose problem been accompanied by itchywatery eyes?"; for atopic eczema "Have you ever had an itchy rash which was coming and going for at least six months?" If yes: Has this itchy rash at any time affected one of the following places: the folds of the elbows, behind the knees, in front of the ankles, under the buttocks, or around the neck, ears, or eyes?" If answers to the above questions were positive the

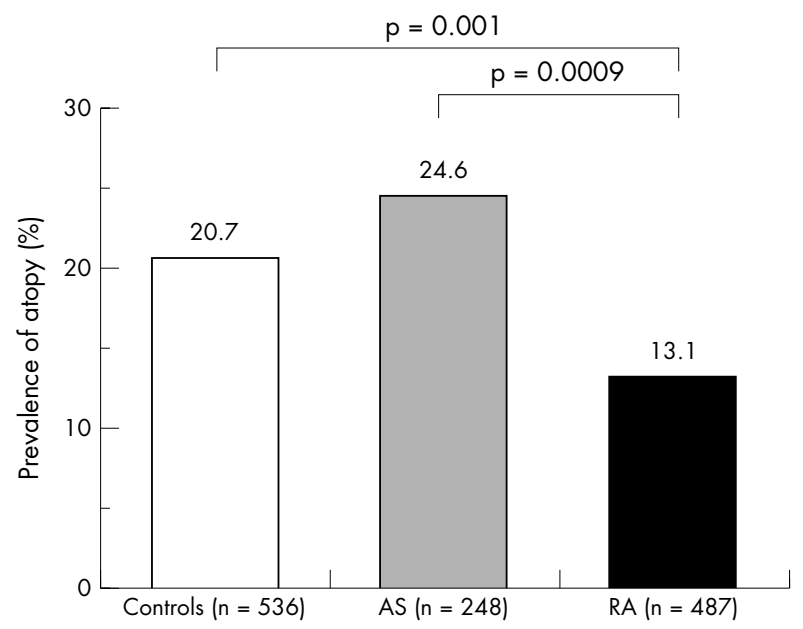

Figure 1 Prevalence (\%) of any atopic disorder in controls, patients with AS, and patients with RA. The differences between AS and RA, and between controls and RA, respectively, were significant as indicated by the $\mathrm{p}$ value.

actual presence of asthma, hay fever, or atopic eczema in that person was already highly likely. However, before considering this person as atopic we required in addition a positive answer to the following question: "Did a doctor or general practitioner ever diagnose you as having asthma, hay fever, or atopic eczema?"

Further questions of the questionnaire were about sex, age, disease duration, onset of AS or RA, onset of the atopic disorder, and other allergies. The modified Health Assessment Questionnaire (mHAQ) was applied to assess disease severity of AS and RA. ${ }^{25}$ For each atopic patient with RA we tried to identify a non-atopic patient with RA among the responders who was matched for sex, age, and disease duration, and assessed details of the patient's drugs, including steroid dosage, by a telephone interview.

\section{Sample size and statistics}

Based on preliminary results, which were fully published later, reporting a $50 \%$ decrease of hay fever in patients with $\mathrm{RA}^{2627}$ and a small pilot study of our own conducted in Berlin and Oxford, UK (Bowness P, personal communication), a power calculation was made for RA: Assuming a response rate to the questionnaire of $60 \%$ we calculated that studying 728 patients with RA would give a power of $80 \%$ to detect a $50 \%$ decrease of hay fever at a significance level of a one sided $p$ value of $\leqslant 0.05$. In the absence of data on atopic disorders in AS no sample size calculation was made for patients with AS and as many patients as possible were considered. A $\chi^{2}$ test, $t$ test, and non-parametric tests such as the Mann-Whitney U test were applied to make comparisons between groups and within groups as appropriate. All statistics were calculated using the computer software SPSS 8.0.

All the methods used in this study were approved by the ethical committee of the Benjamin Franklin Hospital, Berlin.

\section{RESULTS}

\section{Demographic data}

The questionnaire was mailed to 2008 subjects ( 380 patients with AS, 728 RF positive patients with RA, and 900 controls). $248(65.3 \%)$ patients with AS, 487 (66.9\%) patients with RA, and $536(59.6 \%)$ controls responded to the questionnaire. The mean age (SD) was 47.9 (12.3) years in AS, 49.8 (15.6) years in controls, and 60.3 (12.5) years in RA $(p<0.05$ for mean age RA $v$ controls and $v$ AS). The mean (SD) disease duration was 14.1 (10.6) years in patients with AS and 12.2 (9.7) years in patients with RA (table 1). 


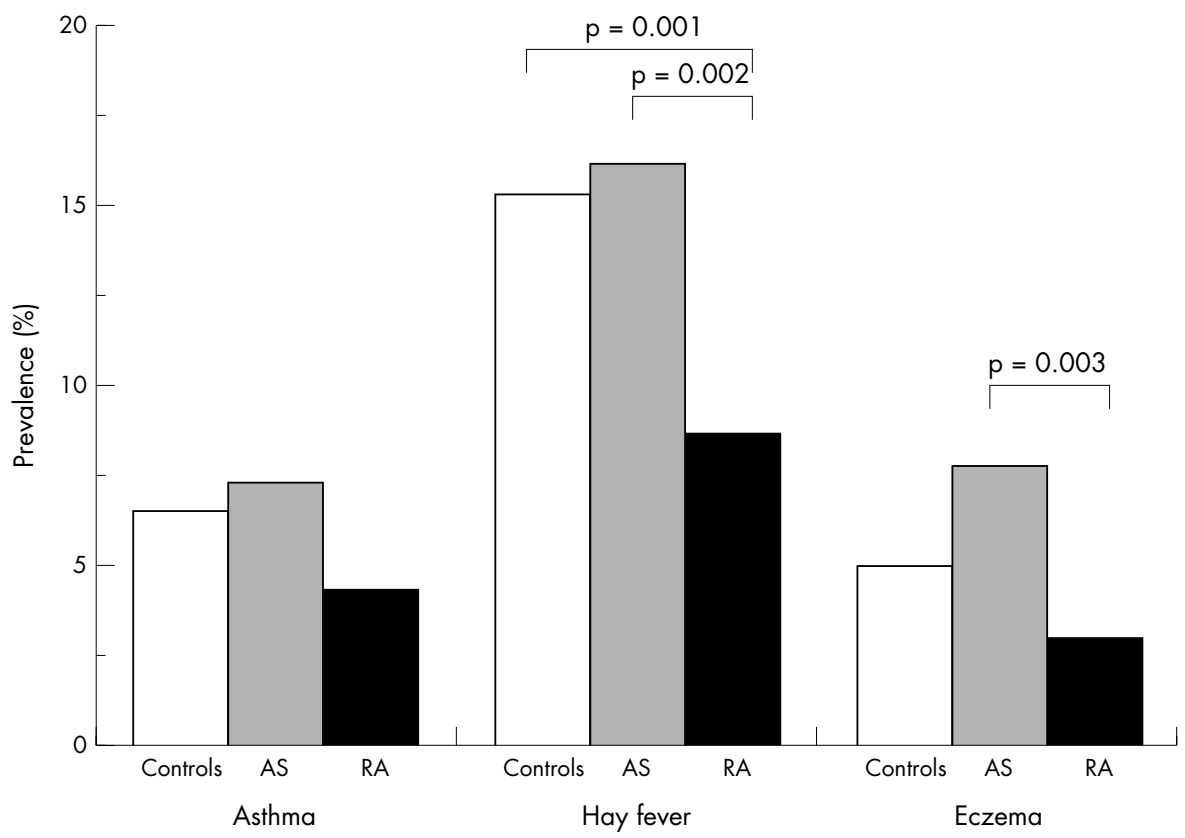

Figure 2 Prevalence (\%) of asthma, hay fever, and atopic eczema in controls ( $n=536)$, patients with AS ( $n=248)$, and patients with RA $(n=487)$. The differences for hay fever between AS and RA, and between controls and RA, and the difference for atopic eczema between AS and RA, respectively, were significant as indicated by the $p$ values.

\section{Prevalence of atopy}

Overall, atopic disorders in AS (24.6\%) were increased compared with RF positive RA (13.1\%; $\mathrm{p}=0.0009$, OR 2.16, 95\%CI 1.46 to 3.19 ) and non-significantly increased compared with controls $(20.7 \%)$, who were ranked in between AS and RA (fig 1). When analysing the various atopic subsets separately the prevalences of asthma, hay fever, and atopic eczema were all highest in AS, intermediate in controls, and lowest in RA. The reported prevalences for asthma were $7.3 \%$ (AS), $6.5 \%$ (controls), and $4.3 \%$ (RA), for hay fever $16.1 \%$ (AS), 8.6\% (RA), and $15.3 \%$ (controls) (AS $v$ RA p $=0.002$, OR $2.04,95 \%$ CI 1.28 to 3.24 ), and for atopic eczema $7.7 \%$ (AS), $4.9 \%$ (controls), and 2.9\% (RA) (AS $v$ RA p=0.003, OR 2.8, $95 \%$ CI 1.38 to 5.69 ), respectively (fig 2 ). Although atopic dis- orders were always higher in patients with AS than in controls the differences were not significant. In patients with RA the prevalences of hay fever (8.6\%) and of any atopy (13.1\%) were significantly decreased compared with controls $(15.3 \%$ and $20.7 \%$, respectively) ( $\mathrm{p}=0.001$, OR $0.52,95 \%$ CI 0.35 to 0.77 for hay fever; and $\mathrm{p}=0.001$, OR $0.58,95 \%$ CI 0.41 to 0.81 for any atopy) (figs 1 and 2 ).

\section{Age and atopy}

Atopic patients with RA were slightly younger than nonatopic RF positive patients with RA (mean age $56.6 \vee 60.9$ years; $p=0.02$ ). Likewise, atopic patients with AS were also slightly younger than non-atopic patients with AS, but this was not significant (mean age $46.6 v 48.3$ years; $p=0.4$ ). To

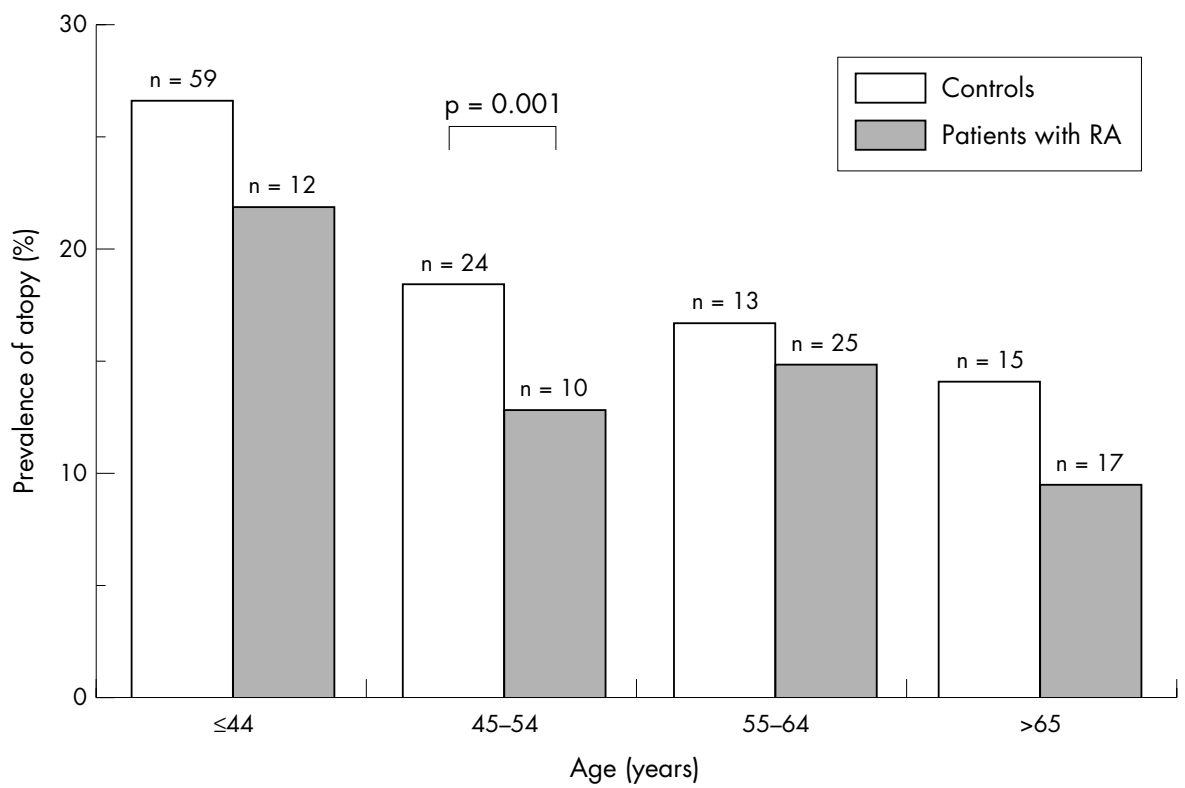

Figure 3 Prevalence of any atopic disorder in controls and in patients with RA according to age. In addition to the percentage, absolute numbers of atopic subjects are also given. A significant difference was found for the 45-54 year age group. 


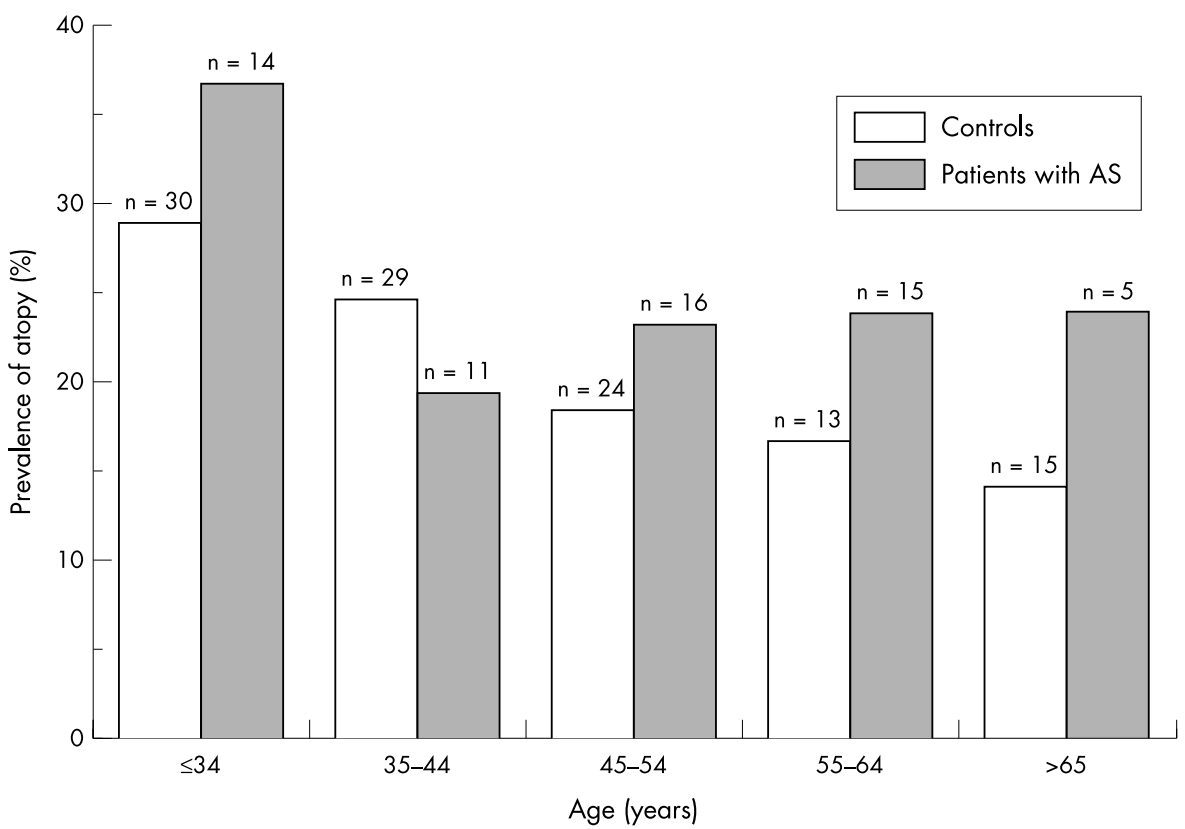

Figure 4 Prevalence of any atopic disorder in controls and patients with AS according to age. In addition to the percentage, absolute numbers of atopic subjects are also given.

assess further any potential influence of age on the differences in the prevalence of atopy we divided the 735 patients (248 with AS and 487 with RA) and 536 controls into the following age groups: $\leqslant 34$ years, $35-44$ years, $45-54$ years, $55-64$ years, and $\geqslant 65$ years. Because the number of very young ( $\leqslant 34$ years) patients with RA was small the youngest RA age group was defined as $\leqslant 44$ years. There was a continuous decrease of atopy with increasing age among the controls and the patients with RA. Figures 3 and 4 show that the trend for a slight increase of atopy in the total AS group and the decrease of atopy in the total RA group compared with controls was not confined to particular age groups but was a consistent finding in almost all age groups. Because numbers within individual age groups became small a significant difference in the prevalence of atopy between RA and controls was found only for the 45-54 years group $(\mathrm{p}=0.001)$ (figs 3 and 4$)$.

\section{Sex and atopy}

The prevalence of atopy was non-significantly higher in female than in male patients with AS (female $27.9 \% v$ male $22.2 \%, \mathrm{p}=\mathrm{NS}$ ) and in controls (female $21.2 \% v$ male $18.7 \%$, $\mathrm{p}=\mathrm{NS})$, whereas virtually no difference was found between female $(13.1 \%)$ and male (13.4\%) patients with RA.

\section{Disease duration and atopy}

The disease duration was neither significantly different between atopic and non-atopic patients with RA (mean disease duration $10.3 v 12.5$ years; $\mathrm{p}=0.16$ ) nor between atopic and non-atopic patients with AS (mean disease duration 13.1 $v 14.5$ years; $\mathrm{p}=0.4$ ).

\section{Disease severity and atopy}

We applied the mHAQ to assess disease severity in both patients with AS and those with RA. The mHAQ in atopic patients with AS $(n=61)$ was not different from that in nonatopic patients with AS $(\mathrm{n}=187)$ (median mHAQ 1.125, 25-75th centile 0.125-1.875 $v$ mHAQ 1.0, 25-75th centile 0.25-1.5). Likewise the mHAQ in atopic patients with RA $(\mathrm{n}=60)$ was similar to that in non-atopic patients with RA $(\mathrm{n}=420)$ (median mHAQ 1.375, 25-75th centile 0.375-2.0 $\mathrm{v}$ mHAQ 1.25, 25-75th centile 0.5-2.25). Among atopic patients with RA the mHAQ was significantly lower in those patients $(n=17)$ who developed their atopic disorder before the onset

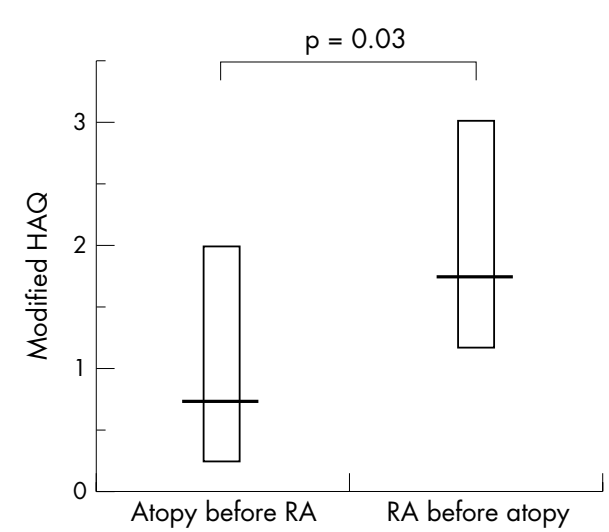

Figure 5 Disease severity assessed by the $\mathrm{mHAQ}$ in atopic patients with RA who experienced the atopic disorder before the onset of RA and in atopic patients who developed RA before the onset of the atopic disorder. Horizontal bars represent the median, open boxes the 25-75th centile. The difference is significant $(p=0.03)$.

of RA than in patients $(n=39)$ who experienced first symptoms of an atopic disorder at the time of or after the onset of RA (median mHAQ $0.75,25-75$ th centile $0.25-2.0 \mathrm{v}$ mHAQ $1.75,25-75$ th centile $1.25-3.0 ; p=0.027$ ) (fig 5). No such significant difference was seen in patients with AS (mHAQ 0.75, 25-75th centile 0-1.75 $v$ mHAQ 1.25, 25-75th centile $0.5-2.25$ in patients with onset of atopy before onset of AS $(n=23)$ compared with patients with onset of AS before onset of atopy $(\mathrm{n}=27) ; \mathrm{p}=0.2)$.

\section{Steroids, immunosuppressive drugs, and atopy}

Drugs may influence the prevalence of atopy. Therefore, all patients with RA with hay fever who agreed to undergo further assessment were compared with patients with RA without hay fever matched for sex, age, and disease duration. Twenty eight such matched pairs were identified who were then interviewed by telephone. Table 2 shows that the drugs used did not differ between atopic and non-atopic patients with RA. In particular, the usage of steroids in the past 12 months was similar in atopic (39\%) and non-atopic (43\%) 
Table 2 Drugs used in atopic and non-atopic patients with RA, matched for age, sex, and disease duration. Results shown as number (\%)

\begin{tabular}{lcc}
\hline & $\begin{array}{l}\text { RA with hay fever } \\
(\mathrm{n}=28)\end{array}$ & $\begin{array}{l}\text { RA without hay } \\
\text { fever }(\mathrm{n}=28)\end{array}$ \\
\hline Prednisolone & $11(39)$ & $12(43)$ \\
NSAIDs & $10(36)$ & $10(36)$ \\
Gold & $3(11)$ & $1(4)$ \\
MTX & $15(54)$ & $18(64)$ \\
Cyclosporin A & $4(14)$ & $4(14)$ \\
Sulfasalazine & $3(1)$ & $4(14)$ \\
TNF blocker & - & $1(4)$ \\
Other DMARDs & $1(4)$ & $2(7)$ \\
\hline
\end{tabular}

patients with RA as was the mean steroid dose (5.9 $v 5.3 \mathrm{mg}$ prednisolone/day) and the mean duration of steroid usage (4.6 $v 3.4$ years). Disease severity measured by the mHAQ was also not significantly different between these two groups (median 1.25 for atopic patients with RA $v$ median 1.75 for non-atopic patients with $\mathrm{RA} ; \mathrm{p}=0.4$ ).

\section{Allergy to latex rubber}

Allergy to latex rubber is increased in hospital workers. A recent study reported a prevalence of $7.3 \%$ for overall clinically relevant rubber latex allergy in German hospital workers. ${ }^{28}$ Because the control group in this study consisted of hospital workers about half of whom were involved in patient care (operating theatres, wards) and the other half in hospital administration we expected a relatively high prevalence of allergy to rubber latex gloves in our control group. Indeed, allergy to rubber gloves was reported by $4.9 \%$ of the controls (hospital workers) compared with 1.2\% among patients with AS and $2.3 \%$ among patients with RA. Thus, reported prevalences of latex rubber allergy show that $(a)$ our control group of hospital workers was representative for a population of hospital workers and $(b)$ patients' reports on allergies appear to be reliable.

\section{DISCUSSION}

AS and RA are both systemic inflammatory rheumatic diseases but differ in many aspects including the local and systemic cytokine pattern. Whereas RA is known to be a strongly Thl polarised disease, ${ }^{81011}$ the cytokine pattern of AS has only recently been investigated and described as an impaired Thl pattern because of low production of INF $\gamma$ and of TNF $\alpha$ but without any relevant change of IL4 production compared with controls. ${ }^{12}{ }^{13}$ Based on the similarities of the cytokine pattern of AS and of Th2 polarised atopic disorders we suggested that AS and atopic disorders may well coexist in a given patient. On the other hand, several lines of evidence suggest that Thl polarised conditions such as RA and Th2 polarised disorders are inversely related. ${ }^{14-172729}$ In this large cross sectional study hay fever, asthma, and atopic eczema were indeed most prevalent among patients with AS, slightly less prevalent among healthy controls, and strongly decreased among patients with RF positive RA. Direct comparison of AS with RA was made possible because both patients with AS and patients with RA derived from the same setting and were studied using identical instruments.

Might the results of our study be influenced by confounding parameters? The large cohorts of patients with AS and RA were representative, in that patients seen by rheumatologists in private practice and in community hospitals as well as patients seen at tertiary academic centres were included in this study. Apart from RF positivity as a prerequisite for the entry of patients with RA no further preselection criteria were applied. The response rates to the questionnaire were similar in AS and RA. Age is potentially a confounding parameter because atopic disorders may decline with increasing age..$^{3031}$ To exclude age as a variable accounting for the differences in the prevalence of atopy we allocated patients according to their age into various age groups, each comprising 10 years. A decline with age was indeed seen in all three groups. Of greater importance, the prevalence of atopy in almost all age groups was again highest in AS, intermediate in controls, and lowest in RA. Thus, age may influence the prevalence of atopy but does not explain the general differences between AS, RA, and the control group.

It is well known that the prevalence of atopic disorders can vary substantially between countries and even between different geographical areas within a country. ${ }^{5}$ Since the reunification of East and West Germany in 1990 an increase of atopic disorders in East Germany took place. This increase has been attributed to the adoption of a "Western lifestyle" which comprises indoor allergens and homing conditions. ${ }^{18-20}$ We took into account this circumstance by recruiting subjects only if they had residency in West Berlin. The control group were representative hospital staff from West Berlin as indicated by the higher rate of allergy to latex rubber.

Immunosuppressive drugs and steroids may influence symptoms of atopic disorders. Because in AS steroids and immunosuppressants are generally not very effective, these drugs are rarely prescribed. In any case such drugs would rather decrease than increase the prevalence of symptomatic atopy and can therefore not account for the trend towards increased prevalence of atopy in AS. On the contrary, the decreased rate of atopy in RA might indeed be related to such drugs. Therefore, atopic patients with RA were compared with non-atopic patients with RA matched for age, sex, and disease duration. No differences in the overall use of steroids, median steroid dose, duration of steroid use, and overall use and type of immunosuppressant drugs were found, suggesting that drugs are unlikely to account for the low prevalence of atopy in RA.

Before this study there were no data on atopic disorders in AS. In RA, however, two recent studies reported a decreased prevalence of hay fever and of any atopic disorder. ${ }^{27}{ }^{29}$ We therefore designed our study to have $80 \%$ power to replicate those findings. In our large cohort of 487 patients with RA the extent of reduction of hay fever (OR 0.58 ) and of any atopic disorder (OR 0.52) was similar to that reported for hay fever (OR 0.48) among 304 Dutch patients with RA and to that reported for any atopic disorder (OR 0.39) among 242 French patients with RA. ${ }^{27} 29$ Thus, our study provides further evidence that RA is indeed associated with a reduced prevalence of atopy. Interestingly, earlier studies in RA already showed decreased levels of IgE and a decreased prevalence of atopy in RA but were inconclusive because of lack of power. ${ }^{32} 33$

Like atopy, pregnancy is another example of the intriguing interaction of Th polarised conditions. A successful pregnancy is generally associated with a Th2 cytokine presence. ${ }^{34}$ If a significant pathogenetic role for the RA- and AS-specific Th cytokine patterns is assumed, a temporary shift towards a Th2 milieu induced by pregnancy should ameliorate the course of RA but worsen the course of AS. In fact, most patients with RA have a milder course of their RA during pregnancy and a flare after delivery. ${ }^{35}$ In contrast, most patients with AS have either an unaltered course or aggravated symptoms when pregnant. ${ }^{36}$ Among many other pregnancy related local, mechanical, and hormonal factors, cytokines may contribute to these differences.

The implications of our study are severalfold: firstly, the data provide strong clinical support for the concept of divergent cytokine patterns in AS and RA. While RA is a Thl polarised disease, AS is definitely not a Thl polarised disease. Secondly, because atopic disorders arise generally before AS 
and RA one can speculate that a state of atopy once established may protect from the later development of RA but not from the development of AS. However, whether a state of atopy may even favour the subsequent development of AS is questionable because in AS there was only a non-significant trend for an increased prevalence of atopy in comparison with controls. Thus, the extent to which atopy may confer susceptibility to AS - if at all-seems to be rather small. Thirdly, atopy may influence the disease course of AS and RA. ${ }^{37}$ Disease severity of AS and RA was measured by the mHAQ in our study and appeared not to be modified by the coexistence of an atopic disorder. However, atopic patients with RA who had atopy before the onset of RA had a better functional status than atopic patients with RA who had RA before the onset of atopy. This suggests a less severe disease course if RA arises when a Th2 milieu is already established by a pre-existing atopic disorder. Fourthly, the Thl/Th2 imbalance appears theoretically as an appealing therapeutic target but seems to be of greater importance in RA than in AS. ${ }^{38}$ The fact that blocking TNF $\alpha$ is therapeutically effective in both RA and $\mathrm{AS}^{39-41}$ suggests that targeting other mediators of inflammation may be clinically more relevant than the restoration of the Th1/Th2 balance.

In summary, we found that atopic disorders are much more prevalent in AS than in RA. In comparison with controls, however, there was only a trend for a higher increase of atopic disorders in AS. The previously reported decrease of atopic disorders in RA is now confirmed. As a result, a state of atopy appears to confer some protection from RA, but only very little-if any-susceptibility to AS. Our findings may further indicate that the cytokine deviation towards the impaired Thl pattern in AS is less strong than the cytokine deviation towards Thl in RA.

\section{ACKNOWLEDGEMENTS}

We thank the participating patients, institutions, and rheumatologists in private practice in West Berlin for access to their database entries. Special thanks to D Nowak, Hamburg, Germany, for discussion and providing the German version of the questionnaire, and to P Bowness, Oxford, UK, for participating in the pilot study.

\section{Authors' affiliations}

M Rudwaleit, B Andermann, J Sieper, J Braun, Rheumatology, University Hospital Benjamin Franklin, Berlin, Germany

R Alten, Rheumatology, Schlossparkklinik, Berlin, Germany

H Sörensen, Rheumatology, Immanuel-Krankenhaus, Berlin, Germany J Listing, A Zink, Epidemiology, Deułsches Rheumaforschungs-zentrum, Berlin, Germany

Current address of Dr J Braun: Rheumazentrum Ruhrgebiet, Landgrafenstrasse 15, 44652 Herne, Germany

\section{REFERENCES}

1 Braun J, Sieper J. The sacroiliac joint in spondyloarthropathies. Curr Opin Rheumatol 1996:8:275-87.

2 McGonagle D, Gibbon W, O'Connor P, Green M, Pease C Emery $P$. Characteristic magnetic resonance imaging entheseal changes of knee synovitis in spondyloarthropathy. Arthritis Rheum 1998:41:694-700.

3 Zink A, Braun J, Listing J, Wollenhaupt J, and the German Collaborative Arthritis Centers. Disability and handicap in rheumatoid arthritis and ankylosing spondylitis - results from the German Rheumatological Database. J Rheumatol 2000;27:613-22.

4 Kay $\mathbf{A B}$. Advances in immunology: allergy and allergic diseases. N Eng Med 2001;344:30-7

5 The international study of asthma and allergies in childhod (ISAAC) steering committee. Worldwide variation in prevalence of symptoms of asthma, allergic rhinoconjunctivitis, and atopic eczema: ISAAC. Lancet 1998;351:1225-32.

6 Del Prete G. Human Th1 and Th2 lymphocytes: their role in the pathophysiology of atopy. Allergy 1992;47:450-5.

7 Abbas AK, Murphy KM, Sher A. Functional diversity of helper T lymphocytes. Nature 1996;383:787-93.

8 Simon AK, Seipelt E, Sieper J. Divergent T-cell cytokine patterns in inflammatory arthritis. Proc Natl Acad Sci USA 1994;91:8562-6.
9 Liblau RS, Singer SM, McDevitt HO. Th1 and Th2 CD4+ T cells in the pathogenesis of organ-specific autoimmune diseases. Immunol Today 1995;34:34-8

10 Schulze-Koops H, Lipsky PE, Kavanaugh AF, Davis LS. Elevated Th 1- or Th0-like cytokine mRNA in peripheral circulations of patients with rheumatoid arthritis. Modulation by treatment with anti-ICAM-1 correlates with clinical benefit. J Immunol 1995; 155:5029-37.

11 Dolhain RJEM, van der Heiden AN, ter Haar NT, Breedveld FC, Miltenburg AMM. Shift toward T lymphocytes with a T helper 1 cytokine-secretion profile in the joints of patients with rheumatoid arthritis. Arthritis Rheum 1996:39:1961-9.

12 Canete JD, Martinez SE, Farres J, Sanmarti R, Blay M, Gomez A, et al. Differential Th1/Th2 cytokine patterns in chronic arthritis: interferon gamma is highly expressed in synovium of rheumatoid arthritis compared with seronegative spondyloarthropathies. J Rheumatol 2000;59:263-8.

13 Rudwaleit $M$, Siegert S, Yin Z, Eick J, Thiel A, Radbruch A, et al. Low T cell production of TNF $\alpha$ and IFN $\gamma$ in ankylosing spondylitis: its relation to HLA-B27 and influence of the TNF-308 gene polymorphism. Ann Rheum Dis $2001 ; 60: 36-42$

14 Shirakawa T, Enormoto T, Shimazu S, Hopkin JM. The inverse association between tuberculin responses and atopic disorder. Science 1997:275:77-9.

15 Prescott SL, Sly P, Holt P. Raised serum lgE associated with reduced responsiveness to DPT vaccination during infancy. Lance 1998;351:1489

16 Oro AS, Guarino TJ, Driver R, Steinman L, Umetsu DT. Regulation of disease susceptibility: decreased prevalence of $\lg \mathrm{E}$-mediated allergic disease in patients with multiple sclerosis. J Allergy Clin Immunol 1996;97:1402-8.

17 The EURODIAB Substudy 2 Study Group. Decreased prevalence of atopic diseases in children with diabetes. J Pediatr 2000; 137:470-4.

18 von Mutius E, Weiland S, Fritzsch C, Nicolai T, Roll G, Thiemann H. Prevalence of asthma and atopy in two areas of West and East Germany. Am J Respir Crit Care Med 1994;149:358-64.

19 Nowak D, Heinrich J, Jörres R, Wassmer G, Berger J, Beck E, et al. Prevalence of respiratory symptoms, bronchial hyperresponsiveness and atopy among adults: West and East Germany. Eur Respir J 1996;9:2541-52

20 von Mutius E, Weiland S, Fritzsch C, Duhme H, Keil U. Increasing prevalence of hay fever and and atopy among children in Leipzig, East Germany. Lancet 1998:351:862-6.

21 Burney PGJ, Luczynska C, Chinn S, Jarvis D for the European Community Respiratory Health Survey. The European Community Respiratory Health Survey. Eur Respir J 1994;7:954-60.

22 Asher MI, Keil U, Anderson HR, Beasley R, Crane J, Martinez F, et al. International study of asthma and allergies in childhood (ISAAC): rationale and methods. Eur Respir J 1995;8:483-91.

23 Pearce N, Weiland S, Keil U, Langridge P, Anderson HR, Strachan D, et al. Self-reported prevalence of asthma symptoms in children in Australia, England, Germany and New Zealand: an international comparison using the ISAAC protocol. Eur Respir J 1993:6:1455-61.

24 Burney PGJ, Laitinen LA, Perdrizet S, Huckauf H, Tattersfield AE, Chinn $\mathrm{S}$, et al. Validity and repeatability of the IUATLD (1984) bronchial symptoms questionnaire: an international comparison. Eur Respir 1989;2:940-5.

25 Pincus T, Summay JA, Soraci Jr SA, Wallston KA, Hummon NP. Assessment of patient satisfaction in activities of daily living using a modified Stanford health assessment questionnaire. Arthritis Rheum 1983;26:1346-53

26 Verhoef CM, Vianen MHE, Lafeber FPJG, Biilsma JWJ. Mutual antagonism of rheumatoid arthritis and hay fever; a role for type 1/type 2 cell balance [abstract]. Arthritis Rheum 1997;40(suppl):S197.

27 Verhoef CM, van Roon JAG, Vianen ME, Bruijnzeel CAFM, Lafeber FPJG, Bijlsma WJ. Mutual antagonism of rheumatoid arthritis and hay fever; a role for type 1/type2 T cell balance. Ann Rheum Dis 1998:57:275-80.

28 Rueff F, Schöpf P, Huber R, Lang S, Kaphhammer W, Przybilla B. Naturlatexallergie. Die verdrängte Berufskrankheit. Dt Ärzteblatt 1999:96:B934-7.

29 Allanore Y, Hilliquin P, Coste J, Renoux M, Menkes CJ. Decreased prevalence of atopy in rheumatoid arthritis. Lancet 1998;351:497.

30 Eriksson NE, Holmen A. Skin prick tests with standardized extracts of inhalant allergens in 7099 adult patients with asthma or rhinitis: cross-sensitizations and relationships to age, sex, month of birth and year of testing. J Investig Allergol Clin Immunol 1996:6:36-46.

31 Hanneuse Y, Delespesse G, Hudson D, de Halleux F, Jacques JM. Influence of ageing on lgE-mediated reactions in allergic patients. Clin Allergy 1978;8:165-74.

32 Peskett SA, Platts-Mills TAE, Ansell BM, Stearnes GN. Incidence of atopy in rheumatic disease. J Rheumatol 1981:8:321-4.

33 O'Driscoll BRC, Milburn HJ, Kemeny DM, Cochrane GM, Panayi GS. Atopy and rheumatoid arthritis. Clin Allergy 1985;15:547-53.

34 Raghupathy $\mathbf{R}$. Th 1-type immunity is incompatible with successful pregnancy. Immunol Today 1997;18:478-82.

35 Nelson JL, Ostensen M. Pregnancy and rheumatoid arthritis. Rheum Dis Clin North Am 1997;23:195-212.

36 Ostensen $\boldsymbol{M}$. The effect of pregnancy on ankylosing spondylitis, psoriatic arthritis, and juvenile rheumatoid arthritis. Am J Reprod Immuno 1992;28:235-7.

37 Gaston JSH. Will the increasing prevalence of atopy have a favourable impact on rheumatoid arthritis? Ann Rheum Dis 1998;57:265-7. 
38 van Roon JA, Lafeber FP, Biilsma JW. Synergistic activity of interleukin-4 and interleukin-10 in suppression of inflammation and joint destruction in rheumatoid arthritis. Arthritis Rheum 2001;44:3-12.

39 Maini RN, Taylor PC. Anti-cytokine therapy for rheumatoid arthritis. Annu Rev Med 2000;51:207-29.

40 Brandt J, Haibel H, Cornely D, Golder W, Gonzalez J, Reddig J, et al. Successful treatment of active ankylosing spondylitis with the anti-tumor necrosis factor alpha monoclonal antibody infliximab. Arthritis Rheum 2000;43:1346-52

41 Van den Bosch F, Kruithof E, Baeten D, De Keyser F, Mielants H, Veys EM. Effects of a loading dose regimen of three infusions of chimeric monoclonal antibody to tumour necrosis factor alpha (infliximab) in spondyloarthropathy: an open pilot study. Ann Rheum Dis 2000;59:428-33.

$\mathrm{ECHO}$

Methotrexate depresses immunoglobulins in children

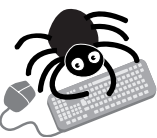

Please visit the Annals of the Rheumatic Diseases website [www. annrheumdis.com] for link to this full article. hildren treated with methotrexate for joint disease show a fall in immunoglobulins, a preliminary study has found. Now the researchers suggest a prospective study, including other inflammatory markers and measuring functional antibody concentrations, to assess the importance of the observation for this second line treatment.

Researchers at the Alder Hey Children's Hospital, Liverpool, UK, made the discovery from a retrospective case review of 78 children in the care of the paediatric rheumatologists there over the past two years. Serum immunoglobulin concentrations fell significantly in the group overall (mean fall in IgG $4.03 \mathrm{~g} / \mathrm{l}$, 26\%; IgA $0.37 \mathrm{~g} / \mathrm{l}, 21 \%$; and IgM $0.25 \mathrm{~g} / 1,17 \%$ ). The results were corroborated for paired samples, which were available for 38 children. Mean fall was larger for methotrexate given subcutaneously than by mouth, and significantly so for IgG. Furthermore, falls in IgG below normal values occurred in six children-all with systemic disease - and all in subclass IgG1. Falls in IgG were not correlated with falls in other inflammatory markers, where data existed for them.

Among the 78 children whose notes were studied, 52 had polyarticular juvenile idiopathic arthritis (JIA), 17 had systemic onset JIA, and nine had other connective tissue diseases. Fifty were receiving low dose $\left(10 \mathrm{mg} / \mathrm{m}^{3}\right)$ methotrexate and 26 medium dose $\left(15-20 \mathrm{mg} / \mathrm{m}^{3}\right)$.

A fall in immunoglobulins with methotrexate treatment has been noted anecdotally by the researchers but has not been studied before.

A Archives of Disease in Childhood 2002;87:147-148. 